\title{
FFC's Advancement of Functional Food Definition
}

\author{
Johanna Gur ${ }^{1}$, Marselinny Mawuntu ${ }^{2}$ and Danik Martirosyan²
}

${ }^{1}$ University of California at Berkeley, Berkeley, CA, USA; ${ }^{2}$ Functional Food Center/Functional Food Institute, Dallas, TX 75252, USA

Corresponding author: Danik Martirosyan, Functional Food Center/Functional Food Institute, Dallas, TX 75252, USA

Submission Date: June $22^{\text {nd }}, 2018$, Acceptance Date: July $28^{\text {th }}$, 2018, Publication Date: July $30^{\text {th }}, 2018$

Citation: Gur J., Mawuntu M., Martirosyan D. FFC's Advancement of Functional Food Definition. Functional Foods in Health and Disease 2018; 8(7): 385-397 DOI: https://doi.org/10.31989/ffhd.v8i7.531

\section{BACKGROUND}

To create functional food products based on scientific evidence, we must first define functional foods. Previous definitions describe how functional foods improve health and mitigate disease. However, more refined definitions provide a reason for their efficacy - through the activity of bioactive compounds and the measurement of biomarkers, which are the essential tools for gauging the effectiveness of functional foods.

Functional foods are generally linked to health promotion. The physiological effects of functional food or bioactive compounds may vary, but their categories of action include physical performance, cognitive, behavioral, and psychological function, organ or system function, and combating chronic disease $[1,2]$.

Therefore, establishing a formal definition for these foods will help bring legitimate functional foods to the market. The addition of bioactive compounds, or biochemical molecules that improve health through the physiological mechanisms, improves the definition of functional foods. As a result, the advancement of the functional food definition by the Functional Food Center (FFC) has developed to provide clarity and a more comprehensive understanding of its meaning.

\section{Previous Definition of Functional Food}

Since 2004, the Functional Foods Center has held international conferences yearly under the series "Functional Foods for the Prevention and Treatment of Chronic Disease." In December of 2009, the 6th International Conference occurred in Texas Women's University in Denton, TX. The annual conference was entitled, "Functional Foods for Chronic Diseases: Diabetes and Related Disease" [3].

One of the goals of the 2009 international conference on Functional Food was to develop a standard definition for functional foods. Main conference topics included a presentation on "Functional Food Definition" by Dr. Danik Martirosyan, who suggested updating the standard 
definition that was published in the conference proceedings and approved by the audience. That definition is as follows:

"Natural or processed foods that contain known or unknown biologically-active compounds; which, in defined, effective, and non-toxic amounts, provide a clinically proven and documented health benefit for the prevention, management, or treatment of chronic diseases" [3].

\section{Bioactive Compounds}

"Bioactive compounds" are chemical components in functional foods that exhibit beneficial biological activities. These bioactive compounds can be considered extra-nutritional constituents that usually occur in small amounts in various food sources. In short, bioactive compounds are beneficial because they act as antioxidants, are chemo- and cardio-preventive, and can even reduce risk or prevent the onset of certain diseases [4].

Scientifically speaking, the term "bioactive" means biologically active [5]. Accordingly, a bioactive compound is a substance that possesses a biological activity [6]. In medicine dictionaries, bioactive compounds are defined as having an effect, causing a reaction, or triggering a response in tissues of the human body [7-9]. Overall, bioactive compounds are considered to be the backbone of functional food effectiveness.

These unique compounds come as two types of components: extra-, non-nutritional constituents or extra-nutritional constituents. Extra- and non-nutritional components of food have beneficial health effects but do not include the essential nutrients. In contrast, extra-nutritional constituents include essential nutrients and typically occur in small food quantities. Additionally, they are studied extensively to evaluate their effects on human health [10-12]. Researchers can perform experiments on these compounds and observe causal relationships between bioactive compounds and overall health outcomes.

From the perspective of functional foods, food bioactive compounds are primary and secondary metabolites with nutritive and non-nutritive natural components that have the potential to positively affect health [13]. Consequently, bioactive compounds can be defined as inherent, non-nutritive constituents of foods with beneficial promotion on health and/or effects of toxicity when ingested [14]. In other words, different amounts of bioactive compounds can be toxic with over-consumption. Bioactive compounds are effective in specific, quantified amounts.

Each bioactive compound has its own unique structure, with physiological mechanisms and concentrations that depend on the environment where it is sourced. Bioavailability varies with the extraction method that is utilized to extract compounds from their source [4]. For example, cooking can alter or eliminate bioactive compounds.

Diet is an essential factor that contributes to health and disease in the normal aging process and affects reactive oxygen species that, ceteris paribus, cause inflammation and cellular damage leading to CVD, diabetes mellitus, obesity, and Alzheimer disease [15-17]. A variety of nutrition profiles consisting of functional foods are recommended in healthy meal plans to protect and manage type 2 diabetes mellitus, or T2DM, such as a Mediterranean diet. Nonetheless, a traditional Mediterranean diet is considered one of the healthiest diets for human longevity based on 
epidemiological studies associating health risk-reduction with Mediterranean Diet style rather than a single component of the diet $[18,19]$. In light of expanding knowledge and education on bioactive compounds in relation to functional food, FFC strives to exponentiate its resources for general public awareness to combat these chronic diseases.

\section{FFC Functional Food Definition (2017)}

The FFC now defines "functional foods" as the following:

"Natural or processed foods that contain biologically active compounds; which, in defined, effective, and non-toxic amounts, provide a clinically proven and documented health benefit utilizing specific biomarkers for the prevention, management, or treatment of chronic disease or its symptoms" [26].

In earlier definitions, the phrase "known or unknown" has been used in relation to biologically active compounds. However, in the current definition, the term "unknown" was excluded because there would be no way to quantify the effects of the bioactive compound if the amount was undefined.

For that reason, changes were made accordingly after the latest discussion at Harvard Medical School conference in September of 2017 with teaching partners: Dr. Dolores del Castillo, Senior Scientist and Head of Food Bioscience group and Francesco Matrisciano, MD, Ph.D. from Loyola University Department of Molecular Pharmacology and Therapeutics in Loyola University Chicago, IL [26]. This change represents one of the significant developments for the current FFC definition for functional foods.

Another change to the previous definition is the addition of "specific biomarkers" as a way to measure disease symptoms. Biomarkers are indicators in the body that give off signals in tissues, organs, or systems. Scientists and researchers use the presence of biomarkers to determine the efficacy of a biological process in functional foods.

To test the effectiveness of a bioactive compound, researchers measure specific biomarkers to identify changes that occur at the cellular level. Researchers can then monitor these changes to measure health or identify disease. Testing specific and sensitive biomarkers help identify the health benefits of bioactive compounds in food. There are a plethora of diseases with symptoms that can be characterized by biomarkers; some common ones include cancer, obesity, cardiovascular disease, diabetes, and emotional and neurological diseases [21].

A final change to the old definition of functional foods is the elaboration of chronic disease "or its symptoms." Potential signs of a disease are also crucial for the treatment of the disease. By including the symptoms of a disease, the definition broadens its scope to include not only the final state of the disease but all the factors that contribute to this final state. With this new definition, functional foods can reach a wider group of individuals.

It is not possible to cure all diseases, with medicine or with food. With this new definition, those suffering from these kinds of diseases will be able to turn to functional foods as a source of potential relief of symptoms, thereby improving the quality of life. Ultimately, the latest FFC 
definition provides a more comprehensive understanding of functional foods, in addition to making the organization's vision and purpose for the advancement of functional foods clearer.

Table 1. Functional Food as Defined by Other Organizations (as adapted from "A New Definition of Functional Food by FFC: What Makes a Definition Unique?" Journal of FFHD)

\begin{tabular}{|c|c|}
\hline \multicolumn{2}{|r|}{ Various Definitions of Functional Food } \\
\hline $\begin{array}{l}\text { The Institute of Food } \\
\text { Technologists (IFT) }\end{array}$ & $\begin{array}{l}\text { "Foods and food components that provide a health benefit } \\
\text { beyond basic nutrition. These substances provide essential } \\
\text { nutrients often beyond quantities necessary for normal } \\
\text { maintenance, growth, and development, and/or other } \\
\text { biologically active components that impact health benefits" } \\
{[22] \text {. }}\end{array}$ \\
\hline $\begin{array}{l}\text { The Institute of Medicine of the } \\
\text { U.S. National Academy of } \\
\text { Sciences }\end{array}$ & $\begin{array}{l}\text { "Foods that encompass potentially healthful products, } \\
\text { including any modified foods or food ingredients that may } \\
\text { provide a health benefit beyond the nutrients it contains" } \\
{[23] .}\end{array}$ \\
\hline $\begin{array}{l}\text { Foods for Special Dietary Use } \\
\text { (As defined by the Federal } \\
\text { Food, Drug, and Cosmetic Act) }\end{array}$ & $\begin{array}{l}\text { "A particular use for which a food purports or is represented } \\
\text { to be used, including to the following: } \\
\text {-Supplying a special dietary need that exists by reason of a } \\
\text { physiological, pathological, or physical condition } \\
\text {-Supplying a vitamin, mineral, or other ingredients for use } \\
\text { by humans to supplement the diet by increasing the total } \\
\text { dietary intake } \\
\text {-Supplying a special dietary need by reason of being a food } \\
\text { for us as the sole item of diet" [20]. }\end{array}$ \\
\hline Food and Drug Administration & $\begin{array}{l}\text { Does not provide a legal definition for the term "functional } \\
\text { foods," which is currently used as a marketing idiom for the } \\
\text { category [24]. }\end{array}$ \\
\hline American Dietetic Association & $\begin{array}{l}\text { Classifies all foods as functional at some physiological level } \\
\text { in that food provides nutrient, growth, or maintain vital } \\
\text { processes [25]. }\end{array}$ \\
\hline FFC Definition (2014) & $\begin{array}{l}\text { "Natural or processed foods that contain known or unknown } \\
\text { biologically-active compounds; which, in defined, effective, } \\
\text { and non-toxic amounts, provide a clinically proven and } \\
\text { documented health benefit for the prevention, management, } \\
\text { or treatment of chronic diseases" [3]. }\end{array}$ \\
\hline
\end{tabular}




\section{Components of the New Functional Food Definition}

Analyzing every part of a definition is important for understanding and explaining each concept.

\section{Figure 1.2. Sectional Parts of the Current FFC “Functional Food" Definition}

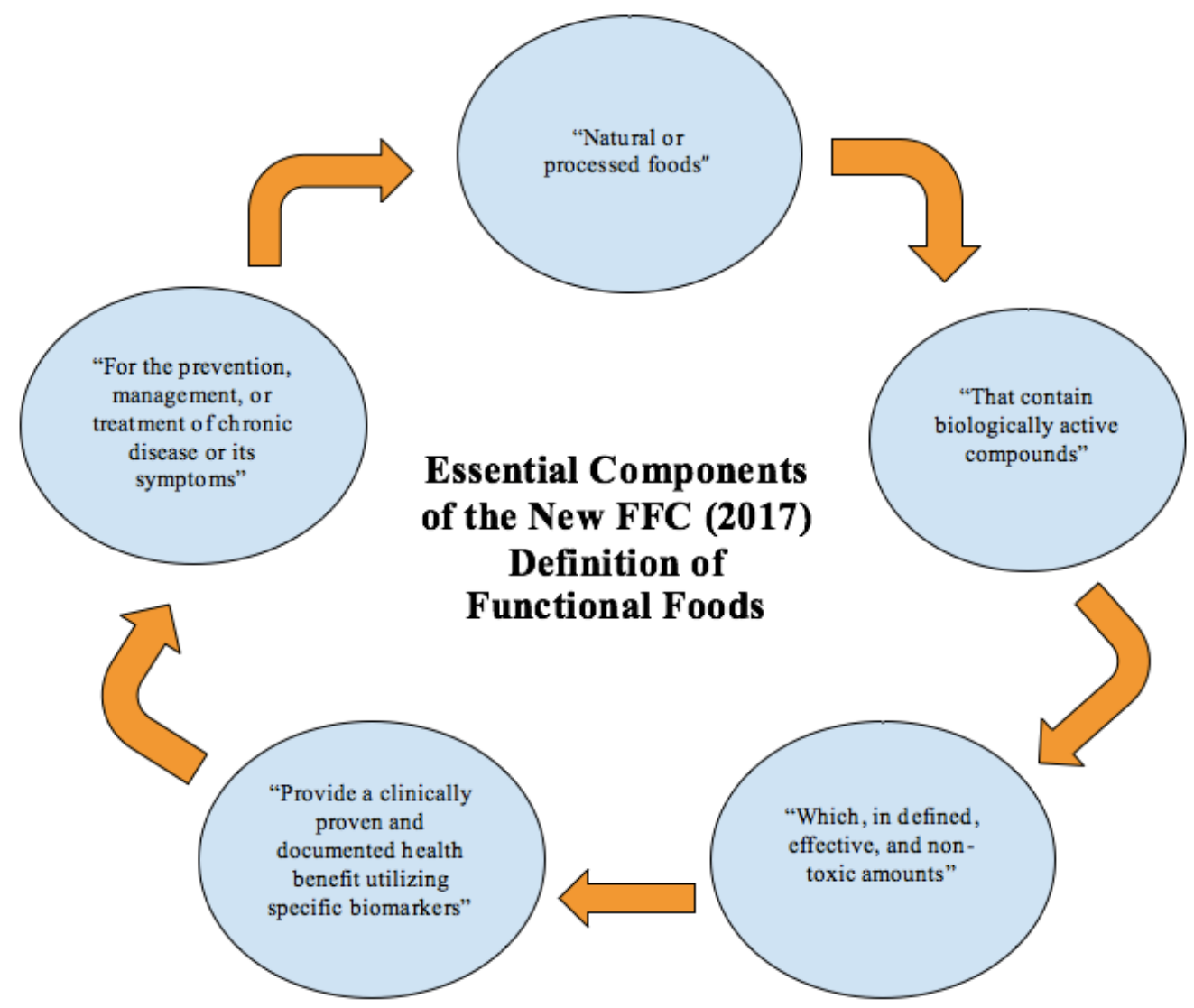

Functional foods are becoming increasingly popular based on their clinically proven health benefits to prevent, manage, and treat chronic diseases. The current definition of functional food is more precise and specific. In the definition, "natural or processed foods" describes the types of foods dealt with in functional foods. The phrase "that contain biologically active compounds" focuses on components from these foods which affect the body. Moreover, "which, in defined, effective, and non-toxic amounts" concentrates more on the quantity, efficacy, and level of toxicity that these foods possess.

The fact that they "provide a clinically proven and documented health benefit utilizing specific biomarkers" means that functional foods allow for successful treatment and there is concrete evidence of the overall impact of their effects. By specifying the use of biomarkers, the definition emphasizes that the "clinically proven health benefits" must be supported by the identification of alterations in the body and signal signs of disease - biomarkers. Lastly, the phrase "for the prevention, management, or treatment of chronic disease or its symptoms" addresses three key elements which functional foods try to achieve: prevent, manage, or treat not only the disease 
itself but also its symptoms. The FFC's inclusion of the last two sections of the most recent definition supports the notion that it is necessary to provide clinically proven benefits as well as treating the disease as a whole [26].

\section{Current State of Regulations}

The discipline of functional food science is an aspect of nutritional science centered upon the research and development of these foods by using both a function-driven approach and a lifestyle approach to prevent and manage diseases, like diabetes [27-31]. The primary challenge is that the United States Food and Drug Administration (FDA) does not have a formal definition of functional foods in the United States. The FDA regulates functional foods under the two laws. The Federal Food, Drug, and Cosmetic Act (FD\&C) of 1938 requires the regulation of all foods and food additives. The Dietary Supplement Health and Education Act (DSHEA) of 1994 amended the FD\&C Act covers diet supplements and ingredients [32, 33].

Current regulations should adequately reflect all foods, including natural, processed, functional, and medical. Once the government and scientists agree upon what exactly makes food "functional," laws can be enacted to encourage research [33, 34]. If we can educate the public properly about functional foods, then they will be able to embrace the concept. A standardized definition would give scientists credibility to educate the public.

\section{Functional Food Regulation}

Instead of relying only on medication to treat diseases, functional food products are another way to combat symptoms and disease. Moreover, if functional foods are valued by consumers because of their ability to prevent and treat chronic diseases or their symptoms, the industry would be discouraged from saturating markets with products that lack concrete evidence to support claims about their benefits [35-37].

When faced with increasing health care costs in the 1980s, Japan's Ministry of Health and Welfare started a regulatory system to approve certain foods with documented health benefits to improve the health of the nation [38]. During that time, the U.S. did not have a standard definition. Years later, in 1994, the National Academy of Sciences' Food and Nutrition Board in the U.S. defined functional foods as "any modified food or food ingredient that may provide a health benefit beyond the traditional nutrients it contains" [39]. The International Life Sciences Institute defined functional foods as "foods that, by virtue of the presence of physiologically active components, provide a health benefit beyond basic nutrition" [40]. The American Dietetic Association defined functional foods as foods that are "whole, fortified, enriched, or enhanced" [41]. Although they vary in specificity and cohesion, these definitions are a step towards the regulation of functional foods.

The Japanese Ministry of Health, Labor, and Welfare was the first regulatory agency to acknowledge functional foods as a unique food category [42]. Since then, Japan has been the leader 
in functional food regulation [43]. Their existing regulations concerning the use of food ingredients are adequate to cover functional food ingredients [44-45]. In the United States, the FDA currently has four categories of claims that food manufacturers can use for labels to convey health information. These categories include: 1) nutrient content claims, 2) structure/function claims, 3) health claims, and 4) qualified health claims [46]. All of these four claim types are allowed on functional food and regular food labels alike if the claim meets the defined criteria.

\section{Steps to Establish Functional Food as a Separate Category}

FFC aims to establish a separate category for the regulation of functional foods, and there are four main steps by which FFC plans to achieve this goal. These four steps will cyclically work to help establish a specific process for regulating functional foods, thereby making them safer and more available for public consumption. One step in this process is educating the public about functional foods. The FFC focuses on this step. The primary goal of FFC is to educate physicians, health professionals, researchers, scientists, students, and the general public about the health benefits, current research, and development of functional foods. Since 1998, FFC has worked to accomplish this goal by hosting 25 international conferences around the globe, upholding two peer-reviewed scientific journals, Functional Foods in Health and Disease (FFHD) and Bioactive Compounds in Health and Disease (BCHD), publishing 30 books including 5 textbooks exclusively on functional food science. Educating the public could, in turn, push the government to approve the current, most recent functional food definition as a standard definition for functional food. Simultaneously, the FFC is contacting government agencies directly to inquire about the process of approving the definition for standardization and urging them to do so.

Ultimately, the organization strives to create standards for the evaluation of functional food products as well as special food labels acceptable to the public. Once proper regulations for production and labeling are established, we must rely on the food industry to understand the research that has been conducted and follow the regulations implemented by the government to begin standardized production of functional foods for public consumption. The food industry will be responsible for developing labels and health claims for functional food products that are clinically proven by the use of biomarkers. Labels should specify "best by" dates to indicate how long bioactive compounds will remain effective. There will also be benefits for the food industry. Functional foods are an untapped sector of the market in which there is substantial potential for financial gains. Unlike medical foods and nutraceuticals, functional foods will be present in stores and accessible to the general public without the need for a prescription from a doctor. Availability of these functional foods will increase exponentially and will benefit both the population and the industry producing these products. 


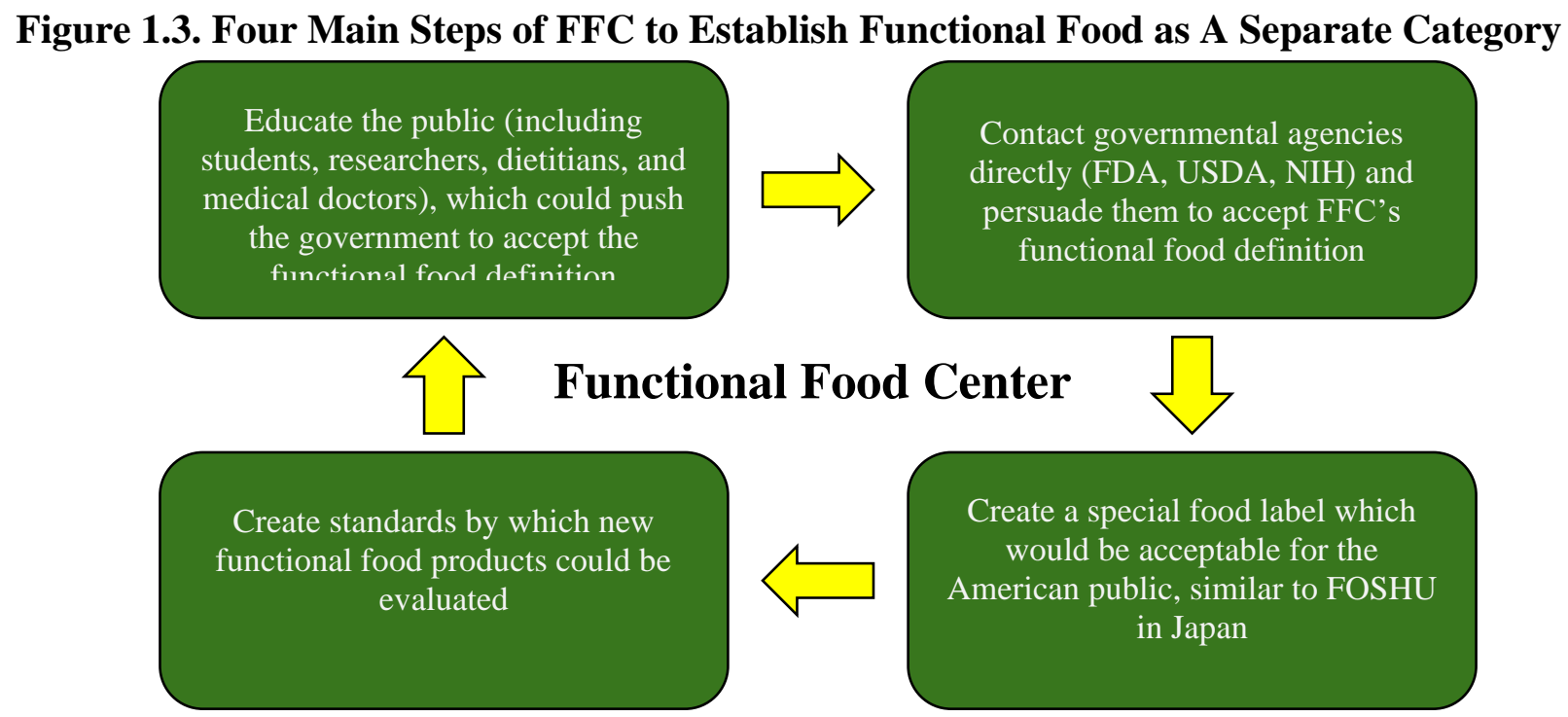

\section{Future Advancements of Functional Food Research}

Extensive research is focused on increasing our understanding of functional foods. For example, there have been several reports that have examined the role of antioxidants in reducing muscle damage since a large increase of oxidative products in exercised muscles via the biomarker of antioxidant intake has been noted [47-51]. Additionally, nutrigenomics is an emerging discipline which investigates the interaction between diet and development of diseases based on an individual's genetic profile [52]. In February 2001, Ventor and a group of colleagues announced the complete sequence of the human genome [53]. This breakthrough discovery can make it possible to tailor a diet for an individual's specific genetic profile. The extensive personalization abilities of nutrigenomics will have a profound effect on the efforts of future disease prevention [54].

Another advancement which will influence the future of functional foods is biotechnology. Recent instances of biotechnology-derived crops have the potential to improve the health of many people worldwide through the use of golden rice and iron-enriched rice [55]. These grains can provide enhanced levels of iron and beta-carotene which could help prevent iron deficiency anemia and vitamin A deficiency-related blindness in the world. Many other foods enhanced with nutritive or non-nutritive substances may even help to prevent chronic diseases, such as cancer, diabetes, and osteoporosis [56] as well as other diet-related disorders in the future.

Research suggests there is significant progress in the field of functional foods. Nutrient bioavailability in foods is governed by the microstructure and composition of the given food, otherwise known as the food matrix [59]. Many studies have shown that in the process of functional food development, interactions within this food matrix between nutrients and nonnutrients can vary in nature [60-61]. As a whole, functional food research has greatly progressed over the years and has shown evidence of remarkable changes in overall health. Its advancements will be an ongoing process of remarkable innovations. For these reasons, it is especially important that the United States develops a standardized definition for the purpose of regulating functional foods in an effort to stimulate more research in the field. 


\section{Evaluating Functional Foods Using FFC's Definition}

As the development of functional foods continues to progress, it will be crucial to confirm that the products we are creating and consuming actually are functional foods. The FFC's definition of functional foods and the steps required to create new functional food products can be used to evaluate scientific evidence and confirm whether a product is a functional food.

FFC has used the refined definition of functional foods to outline the steps necessary for the development of functional foods. This process begins by examining the link between a particular food and health benefits. Once a link has been identified, researchers must determine the bioactive compound that is responsible for the observed health benefit. This is accomplished by running in vitro and in vivo studies with non-living and animal specimens. Once a bioactive compound has been identified, researchers will use in vitro and in vivo studies to determine the mechanism of action that by which the bioactive compound imparts health benefits. Through this step, researchers must also establish a daily value that will deliver effective health benefits to the consumer while avoiding toxicity. Once the mechanism and daily value have been determined, the next step would be conducting human studies. Human studies involve administering humanappropriate doses of bioactive compounds and closely monitoring subjects for any adverse side effects. Once human studies determine the proper dosage of bioactive compounds, an appropriate food vehicle must be developed for the bioactive compounds. This food vehicle combined with the bioactive compound is the functional food product.

The remaining steps in the process involve ensuring proper regulations are met and administering the final product to the public. First, manufacturers must obtain proper labels for functional foods. These labels must include information about daily usage amounts, length of usage, and how long bioactive compounds will remain effective. On labels, manufacturers will need to make health claims that are backed by empirical evidence and closely follow the FDA's health claim regulations. Once the functional food is created and packaged, it must be marketed to the public in a way that adequately educates them about the health benefits of the functional food. Once people begin consuming functional foods, researchers can run epidemiological studies to test for the overall and long-term effectiveness of functional foods and use this information to better inform the future research and functional food development.

To determine if a food is a functional food, we can examine the data provided from research studies and walk through each step of the process to create functional foods and the standards described in the FFC's definition, to see if requirements are met all the way through. If each standard is met, then the product can be considered a functional food. If any standards are not met, the product cannot be considered a functional food. The conclusion may possibly be that there is not enough evidence to determine whether something is a functional food. While this conclusion seems uninformative, it is important because it can be the starting point for more research needed to determine a bioactive compound's potential to be a functional food.

\section{SUMMARY}

Throughout the past decades, FFC has promoted the advancement of functional food research and expanded the scope of its definition of functional food. In order to create functional food products based on scientific evidence, defining them is a crucial first step. 
Previous definitions vaguely state that functional foods improve health and reduce the likelihood of disease. However, FFC's current definition provides a clearer sense of what functional foods do by specifying the activity of bioactive compounds and use of biomarkers to determine functional food effectiveness, as well as broadening the scope of their effects from just a disease to a disease and its symptoms. FFC's advancing approach accomplishes what they believe to be an attainable standard for developing improved functional foods for a better quality of life.

Establishing a more formal and standard definition for functional foods will help bring a greater number of legitimate functional foods to the market in order to benefit a broader range of individuals. This will create a need for more concrete regulation and evaluation of scientific evidence in regards to functional foods. The FFC's definition of functional foods provides the guidelines necessary to accomplish this. FFC's advancement of the definition will, in turn, create more awareness and understanding of functional foods in today's modern society.

List of Abbreviations: FFC, Functional Food Center; ADA, American Dietetic Association; ASFFBC, Academic Society for Functional Foods and Bioactive Compounds; CVD, Cardiovascular Disease; CFFS, Certified Functional Food Scientist; FDA, Food and Drug Administration; IFS, Institute of Food Technologists; MD, Mediterranean diet; T2DM, Type 2 Diabetes Mellitus.

Competing Interests: Authors declare no conflicts of interest.

Authors' Contributions: Danik Martirosyan, PhD. conceived of the idea and coordinated the review of the manuscript. Marselinny Mawuntu, CFFS, and Johanna Gur are student interns who contributed to the writing and editing of the full manuscript. All authors approved the final version before submission.

\section{REFERENCES}

1. Dhiman A, Walia, Vaibhav, Nanda A: "Introduction to the Functional Foods." Introduction to Functional Food Science: Textbook. 2nd ed. Richardson, TX: Functional Food Center; 2014.

2. Westmark CJ: "Definition of Functional Food. Healthy, Functional, and Medical Foods. Similarities and Differences between these Categories. Bioactive Food Compounds." Introduction to Functional Food Science: Textbook. 2nd ed. Richardson, TX: Functional Food Center; 2014.

3. Martirosyan D, Prasad C: Functional Foods for Chronic Diseases: Diabetes and Related Diseases. In The 6th International Conference proceedings; 2009.

4. Martirosyan D, Pisarski K: Bioactive Compounds: Their Role in Functional Food and Human Health, Classifications, and Definition. In "Introduction to Functional Food Science." 3rd ed. Edited by Martirosyan D. Dallas, TX: Food Science Publisher; 2015.

5. Nahler G: Dictionary of Pharmaceutical Medicine. 3rd ed. B letter, Springer-Verlag Wien; 2013: 19-28. 
6. Solomon HK, William WW: Bioactive Food Components, Encyclopedia of Food and Culture. 2nd Ed. Acceptance to Food Politics, B Letter, Charles Scribner's Sons; 2003, 1: 201.

7. Kris-Etherton PM, et al.: Bioactive compounds in foods: their role in the prevention of cardiovascular disease and cancer. American Journal of Medicine 2002, 113(Suppl 9B): 71S-88S.

8. Schrezenmeir J et al.: Foreword. British Journal of Nutrition 2000, 84(S1): 1.

9. Gry J et al.: EuroFIR-BASIS - a combined composition and biological activity database for bioactive compounds in plant-based foods. Trends in Food Science and Technology 2007, 18(8): 434-444.

10. Cammack R et al.; Oxford Dictionary of Biochemistry and Molecular Biology. 2nd ed. Oxford UP; 2006: 74-75.

11. Dictionary of Food Science and Technology. 2nd Ed. International Food Information Service (IFIS Editor); 2009: 47-48.

12. The American Heritage Medical Dictionary. Houghton Mifflin Company; 2007: 47.

13. Mosby's Dictionary of Medicine, Nursing and Health Professions. 9th ed. Mosby Creator; 2013: 83.

14. Miller-Keane, Marie TO: Miller-Keane Encyclopedia and Dictionary of Medicine, Nursing and Allied Health. 7th ed. Saunders; 2005: 62.

15. Scarmeas N, Stern Y, Tang MX, Mayeux R, Luchsinger JA: Mediterranean diet and risk for Alzheimer's disease. Ann. Neurol 2006, 59: 912-921.

16. Saura-Calixto F, Goni I: Definition of the Mediterranean diet based on bioactive compounds. Crit Rev Food Sci Nutr 2009, 49: 145-152.

17. Salas-Salvado J, Bullo M, Estruch R, Ros E, Covas MI, Ibarrola-Jurado N, Corella D, et al: Prevention of diabetes with Mediterranean diets: A subgroup analysis of a randomized trial. Ann Intern Med 2014, 160: 1-10.

18. Salas-Salvado J, Fernandez-Ballart J, Ros E, Martinez-Gonzalez MA, Fito M, Estruch R, et al.: Effect of a Mediterranean diet supplemented with nuts on metabolic syndrome status: One-year results of the PREDIMED randomized trial. Arch Intern Med 2008, 168: 24492458.

19. Trichopoulou A, Costacou T, Bamia C, Trichopoulos D: Adherence to a Mediterranean diet and survival in a Greek population. N Engl J Med 2003, 348:2599-2608.

20. Martirosyan D, Singh J: A New Definition of Functional Food by FFC: What Makes a Definition Unique? Journal of Functional Foods in Health and Disease 2015, 5(6): 209-223.

21. Clydesdale F: "Functional foods: opportunities and challenges." Food Tech 2004, 58.12: $35-40$.

22. Institute of Food Technologists. Functional foods: Opportunities and challenges. March 2005.

23. Thomas PR, Earl R: Opportunities in the Nutrition and Food Sciences: Research Challenges and the Next Generation of Investigators. Edited by the Institute of Medicine's Food and Nutrition Board (IOM/NAS). Washington, DC: National Academies Press; 1994: 98-142. 
24. Martirosyan D, Singharaj B: Health Claims and Functional Food: The Future of Functional Foods under FDA and ESFA Regulation. In "Functional Food and Chronic Disease." Edited by Martirosyan D. Dallas, TX: Food Science Publisher; 2015.

25. American Dietetic Association: Position of the American Dietetic Association: functional foods. Journal of the American Dietetic Association 1999, 99: 1278-1285.

26. Functional Food Center-Functional Food Institute [www.functionalfoodscenter.net]

27. Bellisle R, Diplock AT, Hornstra G, et al.: Functional food science in Europe. Br J Nutr 1998, 80(suppl):S3-193.

28. Diplock AT, Aggott PJ, Ashwell M, et al.: Scientific concepts of functional foods in Europe: consensus document. Br J Nutr 1999, 81(suppl):S1-27

29. Clydesdale F: A proposal for the establishment of scientific criteria for health claims for functional foods. Nutr Rev 1997, 55:413-22.

30. Block G: Micronutrients and cancer: time for actions? Journal of the National Cancer Institute 1993, 85: 846-848.

31. Alkhatib, Ahmad, et al.: Functional Foods and Lifestyle Approaches for Diabetes Prevention and Management. Nutrients 2017, 9(12): 1310.

32. Hasler CM: Functional Foods: Benefits, Concerns and Challenges-A Position Paper from the American Council on Science and Health. The Journal of Nutrition 2002, 132: 37723781.

33. Hoy-Rosas J, Arrecis E, Avila M: Central American Food Practices. In Cultural Food Practices. Edited by Goody C, Drago L. U.S.: American Dietetic Association; 2010: 54-67.

34. Mahan LK, Escott-Stump S, Raymond JL, Janice LK, Marie V (eds.): Krause's Food and The Nutrition Care Process. 13th ed. St. Louis, MO: Elsevier/Saunders; 2012.

35. Nelms M, Sucher KP, Roth S, Lacey : Nutrition Therapy Pathophysiology. 2nd ed. Belmont, CA: Cengage Learning; 2010.

36. Mazza G: Functional Foods: Biochemical and Processing Aspects. Lancaster, PA: Technomic Publishing; 1998.

37. Wildman REC (ed.): Handbook of Nutraceuticals and Functional Foods. Boca Raton, FL: CRC Press; 2001.

38. Arai S: Studies on functional foods in Japan — state of the art. Biosci Biotechnol Biochem 1996, 60: 9-15.

39. Committee on Opportunities in the Nutrition and Food Sciences, Food and Nutrition Board, Institute of Medicine: Enhancing the food supply. In: Opportunities in the Nutrition and Food Sciences: Research Challenges and the Next Generation of Investigators. Edited by Thomas P R, Earl R. National Academy Press, Washington, DC; 1994: 98-142.

40. International Life Sciences Institute. Safety assessment and potential health benefits of food components based on selected scientific criteria. ILSI North America Technical Committee on Food Components for Health Promotion. Crit Rev Food Sci Nutr 1999, 39: 203-316.

41. American Dietetic Association. Position of the American Dietetic Association: functional foods. J Am Diet Assoc 1999, 99: 1278-1285.

42. International Life Sciences Institute: Perspectives on ILSI's international activities on functional foods. May 2009. 
43. Yamada K, Sato-Mito N, Nagata J, Umegaki K: Health Claim evidence requirements in Japan. J Nutr 2008, 138(6): 1192S-1198S.

44. Thompson AK, Moughan PJ: Innovation in the foods industry: Functional foods. Innov Manage Policy Pract 2008, 10(1): 61-73.

45. Henry CJ: Functional foods, editorial. Eur J Clin Nutr 2010, 64(7): 657-659.

46. US General Accounting Office: Food safety: Improvements needed in overseeing the safety of dietary supplements and "functional foods." 2000.

47. Aoi W, Naito Y, Takanami Y, Kawai Y, Sakuma K, Ichikawa H, et al.: Oxidative stress and delayed-onset muscle damage after exercise. Free Radic Biol Med 2004, 37: 480-487.

48. Phillips T, Childs AC, Dreon DM, Phinney S, Leeuwenburgh C: A dietary supplement attenuates IL-6 and CRP after eccentric exercise in untrained males. Med Sci Sports Exerc 2003, 35: 2032-2037.

49. Takanami Y, Iwane H, Kawai Y, Shimomitsu T: Vitamin E supplementation and endurance exercise. Are there benefits? Sports Med 2000, 29: 73-83.

50. Kanter MM, Nolte LA, Holloszy JO: Effects of an antioxidant vitamin mixture on lipid peroxidation at rest and postexercise. J Appl Physiol 1993, 74: 965-969.

51. Aoi W, Naito Y, Sakuma K, Kuchide M, Tokuda H, Maoka T, et al.: Astaxanthin limits exercise-induced skeletal and cardiac muscle damage in mice. Antioxid Redox Signal 2003, 5: $139-144$.

52. Fogg-Johnson N, Meroli A: Nutrigenomics: the next wave in nutrition research. Nutraceuticals World 2000, 3: 86-95.

53. The Celera Genomics Sequencing Team: The sequence of the human genome. Science 2001, 291: 1304-1351.

54. Gura, T: New genes boost rice nutrients. Science (Washington, DC) 1999, 285: 994-5.

55. Institute of Food Technologists. IFT expert report on biotechnology and foods. Food Technol 2000, 54: 61-80.

56. Falk MC, Chassy BM, Harlander SK, Hoban TJ, McGloughlin MN, Akhlaghi AR: Food biotechnology: benefits and concerns. J Nutr 2002, 132: 1384-1390.

57. Shimizu M, Hachimura S: Gut as a target for functional food. Trends Food Sci Technol 2011, 22(12): 646-650.

58. Ross S: Functional foods: The Food and Drug Administration perspective. Am J Clin Nutr 2000, 71(6 suppl): 1735S-1738S.

59. Hwang J, Sevanian A, Hodis HN, Ursini F: Synergistic inhibition of LDL oxidation by phytoestrogens and ascorbic acid. Free Radic Biol Med 2000, 29(1): 79-89.

60. Jeffery E: Component interactions for efficacy of functional foods. J Nutr. 2005, 135(5):1223-1225.

61. Yeum KJ, Russell RM, Krinsky NI, Aldini G: Biomarkers of antioxidant capacity in the hydrophilic and lipophilic compartments of human plasma. Arch Biochem Biophys. 2004, 430(1): 97-103. 